\title{
Control of Pole-Climbing Robot Orientation Using Self-Tuning Method
}

Muhammad Aziz Muslim, Goegoes Dwi Nusantoro, Rini Nur Hasanah, Mokhammad Hasyim Asy’ari Electrical Engineering Department, Faculty of Engineering, Brawijaya University, Indonesia

\begin{tabular}{l}
\hline \hline Article Info \\
\hline Article history: \\
Received May 6, 2018 \\
Revised Jul 11, 2018 \\
Accepted Jul 22, 2018 \\
\hline
\end{tabular}

\section{Keyword:}

Controller

Hybrid robot

Self-tuning method

\begin{abstract}
This paper describes the method to control a hybrid robot whose main task is to climb a pole to place an object on the top of the pole. The hybrid poleclimbing robot considered in this paper uses 2 Planetary PG36 DC-motors as actuators and an external rotary encoder sensor to provide a feedback on the change in robot orientation during the climbing movement. The orientation control of the pole-climbing robot using self-tuning method has been realized by identifying the transfer function of the actuator system under consideration, being followed with the calculation of control parameters using the self-tuning pole-placement method, and furthermore being implemented on the external rotary encoder sensor. Self-tuning poleplacement method has been explored to control the parameters $\mathrm{q}_{0}, \mathrm{q}_{1}, \mathrm{q}_{2}$, and $\mathrm{p}_{1}$ of the controller. The experiments were done on a movement path in a form of a cylindrical pole. The first experiment was done based one the change in rotation angle of the rotary sensor with the angle values greater than $50^{\circ}$ in the positive direction, whereas the second experiment was done with the angle values greater than $-50^{\circ}$ in the negative direction. The experiment results show that the control of the robot under consideration could maintain its original position at the time of angle change disturbance and that the robot could climb in a straight direction within the specified tolerance of orientation angle change.
\end{abstract}

Copyright $\odot 2018$ Institute of Advanced Engineering and Science. All rights reserved.

\section{Corresponding Author:}

Rini Nur Hasanah,

Electrical Engineering Department, Faculty of Engineering,

Brawijaya University,

Jalan MT Haryono 167 Malang 65145, Indonesia

Email: rini.hasanah@ub.ac.id

\section{INTRODUCTION}

Robots can replace human beings in accomplishing many complex or even dangerous tasks.The application of pole climbing robot for wiring and repairing distribution lines [1-3], climbing trees [4-6], in industries [7-9], are some examples. It reduces the risk for human beings, and offers higher working speed and efficiency. Some pole robot utilizes linear motor [2], servo motors [5], DC motor [8], or even without motors [1], which can be operated and controlled remotely [1,2]. Various algorithms have also been implemented accordingly to control the climbing process, for example a sliding mode control being combined with a linear quadratic regulator and dead reckoning [7], or even just a simple P control [8].

This paper describes the design and realization of a control system in a hybrid robot being capable of climbing a pole to place an object on the top of the pole. When the robot moves upward, the robot must maintain its orientation. This is a challenging work, because the robots often experience slippage due to the force of gravity and the weight of the robot. The hybrid pole-climbing robot uses only 2 Planetary PG36 DCmotors as actuators based on the feedback given by an external rotary encoder sensor. The self-tuning poleplacement control method has been applied. The aim was to create a pole-climbing robot being capable of 
adjusting its position and orientation by itself using only 2 actuators with good response and tolerance-error of the robot orientation as small as possible.

The choice of planetary DC motor as actuator was due to its ability to adjust the rotation orientation angle of the steering robot which possesses high torque and rotation speed response [8]. Pole-placement controller was chosen as it is widely known to have fast response [10-15]. The change in the orientation angle of the robot can be adjusted automatically by the planetary DC motor based on the feedback of the rotary encoder sensor. The motor itself already contains a rotary encoder so that its rotation speed precision can be controlled. The use of an external rotary encoder sensor was to facilitate the reading of robot rotation orientation change [16-18].

The Extended Least Square method using the Auto Regressive with Exogenous structure was adopted to determine the estimation parameters of the control design based on the transient response characteristics of the plant under consideration [19-23]. The implementation of the pole-placement controller will give a good result if the proper tuning can be performed, to realize a self-tuning control method [10-15].

\section{ORIENTATION CONTROL OF POLE-CLIMBING ROBOT}

A pole-climbing robot should maintain its orientation while moving upward or downward, despite of gravitational and frictional forces. Top perspective of a pole-climbing robot used in this study is shown in Figure 1. The robot is equipped with 2 Planetary PG36 DC-motors as actuators and an external rotary encoder sensor to provide a feedback on the change in robot orientation during the climbing movement. This paper proposed self tuning of pole-placement controller to control orientation of pole-climbing robot. The control system consists of online identification of process parameters and pole-placement algorithm. An offline system identification is performed first, to provide initial values and to speed up the online identification of process parameters. Such offline system identification is performed using Matlab software. The rest of the work, including microcontroller (i.e Arduino Mega 2560) programming is performed using $\mathrm{C}++$.

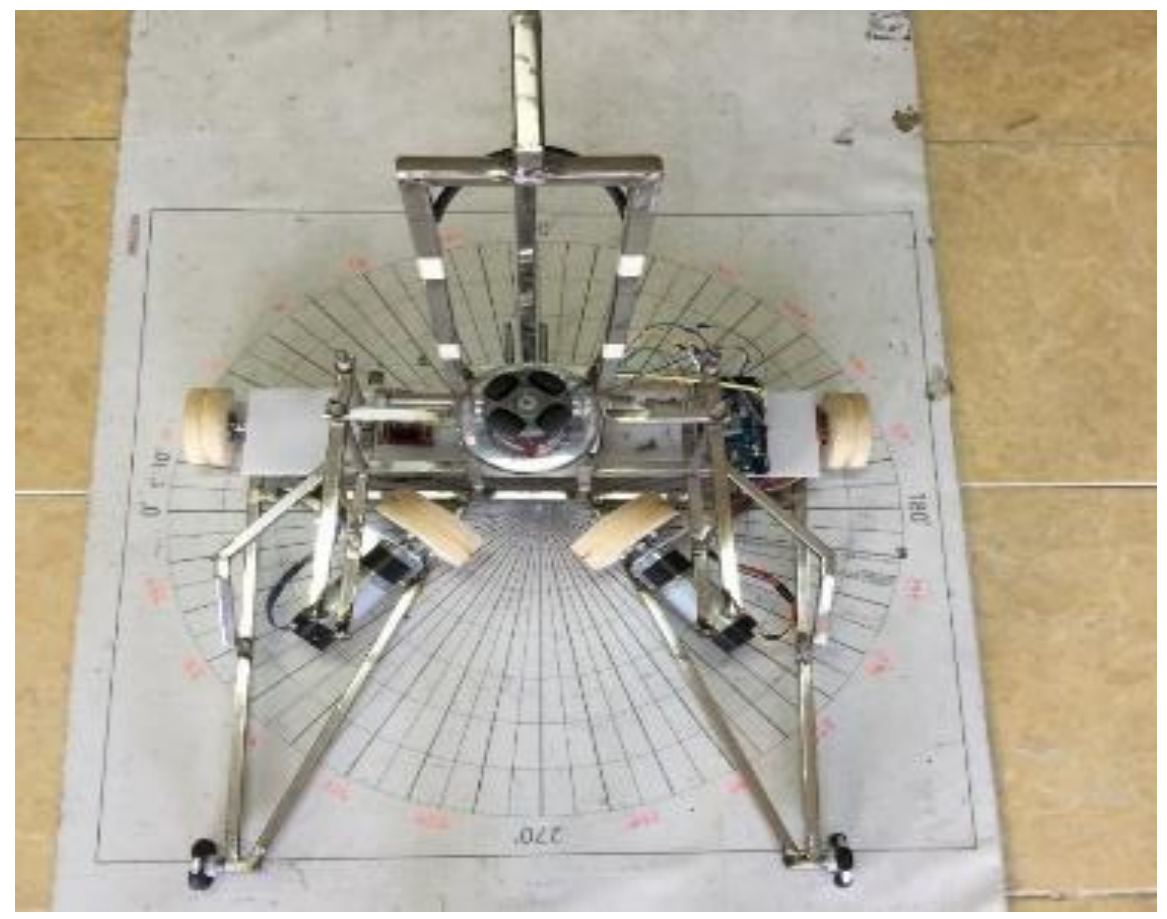

Figure 1. A pole-climbing robot

\subsection{Design of the control system}

The purpose of this research was to design and realize a control system of a hybrid pole-climbing robot. The block diagram of the system is given in Figure 2. 


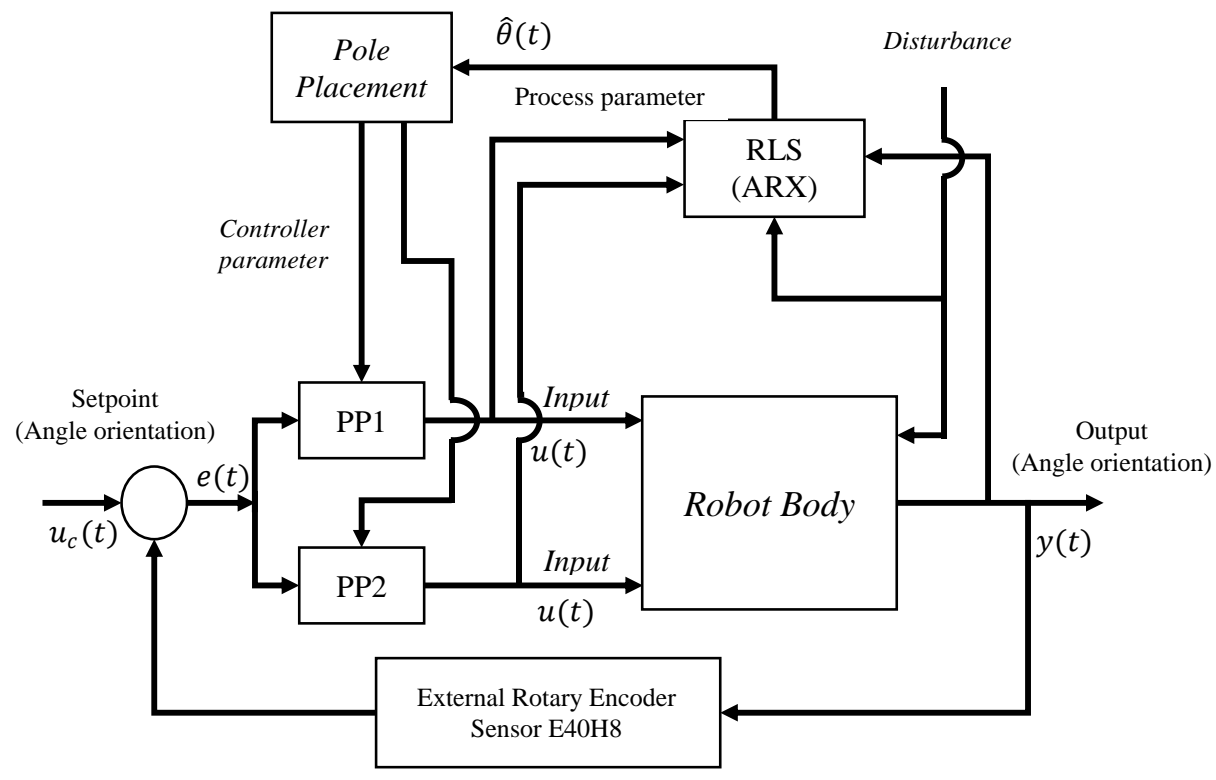

Figure 2. The block diagram of the control system

As seen in Figure 2, the specified setpoint is the desired angle position in order that the robot movement will be straightly directed to the target without involving any rotating movement. It means that the rotation angle is $0^{\circ}$. This movement involves the pole-placement controller, the Planetary PG36 DC motor as actuator, and the orientation of the robot as the plant to be controlled.

As a disturbance is defined as a signal which tends to influence the output of the system negatively, it is the change in the orientation of the angle which becomes the disturbance. If the disturbance is generated inside the system, it is called as the internal disturbance. The external disturbance is generated outside the system and can be considered as an input. The sensor to be used is a mechanical sensor, i.e. the external rotary encoder sensor, to detect the change in the robot rotation orientation during the pole climbing.

The hardware system of the robot is given in Figure 3. As shown, it describes the working principle as well as required components in the system since the power supplying up to the serial data sending to a laptop/computer.

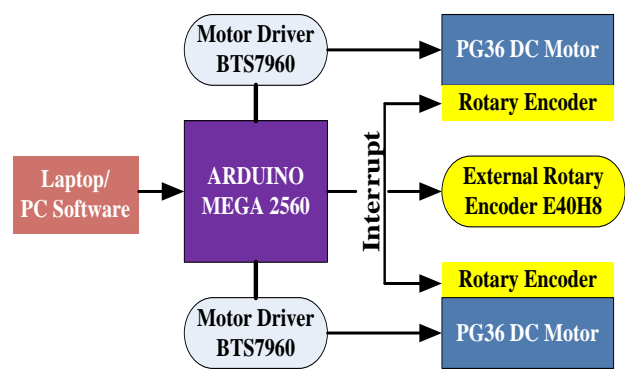

(a)

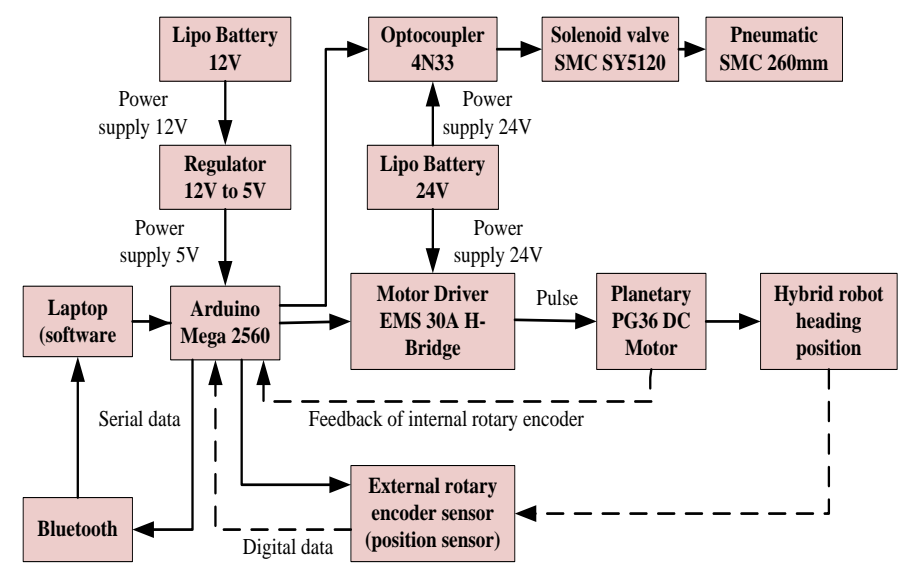

(b)

Figure 3. The hardware system of the pole-climbing robot, a) schema, b) working principle 
The operation of the control system is done through a sequence of instructions as described in a form of flowchart of Figure 4.

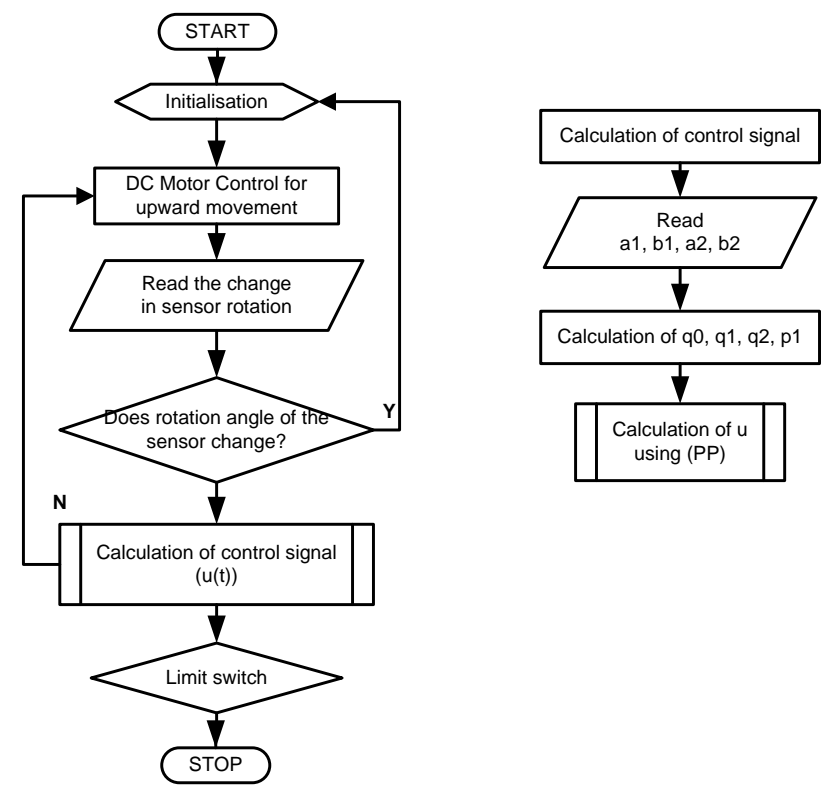

Figure 4. The flowchart of the control operation of the system

\subsection{Determination of the transfer function of planetary PG36 DC motors system}

The pole-climbing hybrid robot considered in this paper uses the Planetary PG36 DC motor as it works well and optimally at the voltage of $24 \mathrm{~V}$. It is used to climb the pole as it also has sufficiently large torque at $24 \mathrm{~V}$, i.e. $20 \mathrm{~kg} / \mathrm{cm}$. The considered maximum duty-cycle of the DC motor is $80 \%$ because the motor is capable to work optimally at the speed of pole climbing process. The mechanical sensor chosen is the external rotary encoder sensor E40H8 from Autonics due to its good repution during the data reading. The desired error angle is $0^{\circ}$, with the maximum tolerance angle during the experiment is $10^{\circ}$.

The transfer function determination of the planetary PG36 DC motors has been done by modeling it through the generation of Pseudo Random Binary Sequence (PRBS) signals. The linear values on the highpulse $\left(\mathrm{T}_{\text {on }}\right)$ of the PG36 motor were to be found out to specify the upper and lower limits of the linear values. The generated PRBS signals with the PWM limit of 140-200 and the related data were then used as the input and output of the identification system [24-25]. The identification system resulted in the transfer functions of Motor 1 and Motor 2. The output characteristics of both motors have been obtained by implementing a unit step function input, and comparing the rise time and the settling time on both motors.

\subsection{Determination of the process parameters}

The initial values of the estimation parameters have been determined using the digital control equation based on the Auto Regressive with Exogenous (ARX) model, as given in Equation 1-3 [26-28].

$A(q) y(k)=B(q) u(k-n k)+e(k)$

with

$A(q)=1+a_{1} q^{-1}+a_{2} q^{-2} \ldots+a_{n a} q^{-n a}$

$B(q)=b_{1} q^{-1}+b_{2} q^{-2} \ldots+b_{n b} q^{-n b}$

where

$\mathrm{y}(\mathrm{k})$ is the input

$\mathrm{u}(\mathrm{k})$ is the output

$\mathrm{e}(\mathrm{k})$ is the disturbance 
In order to control the robot orientation and good performance, it is necessary to find out the transfer function of both the motor actuator systems, as a function of the related parameters $a_{1}, a_{2}, b_{1}$, and $b_{2}$. The resulted parameters are going to be used in the identification process to find out the control parameter values of $\mathrm{q}_{0}, \mathrm{q}_{1}, \mathrm{q}_{2}$, and $\mathrm{p}_{1}$, which can be obtained using the following equations.

$\mathrm{q}_{0}=\frac{\mathrm{r}_{2}-\mathrm{r}_{3}}{\mathrm{r} 1}$

$\mathrm{q}_{1}=-\frac{\mathrm{r}_{4}+\mathrm{r}_{5}}{\mathrm{r}_{1}}$

$\mathrm{q}_{2}=\frac{\mathrm{d}_{4}+\mathrm{p}_{1} \cdot \mathrm{a}_{2}}{\mathrm{~b} 2}$

$\mathrm{p}_{1}=\frac{\mathrm{r} 6}{\mathrm{r} 1}$

The calculated parameters are then converted into the controller equation as follows.

$\mathrm{u}(\mathrm{k})=\mathrm{q}_{0} \mathrm{e}(\mathrm{k})+\mathrm{q}_{1} \mathrm{e}(\mathrm{k}-1)+\mathrm{q}_{2} \mathrm{e}(\mathrm{k}-2)+\left(1-\mathrm{p}_{1}\right) \mathrm{u}(\mathrm{k}-1)+\mathrm{p}_{1} \mathrm{u}(\mathrm{k}-2)$

Equation 8 has been used to control the plant based on the involved parameters values obtained.

\section{RESULTS AND ANALYSIS}

\subsection{Transfer functions of the actuator system}

Some model estimations using some data variations of some different motors resulted in the transfer function of the Planetary PG36 DC motors, as given in Figure 5 for Motor 1 and Figure 6 for Motor 2.

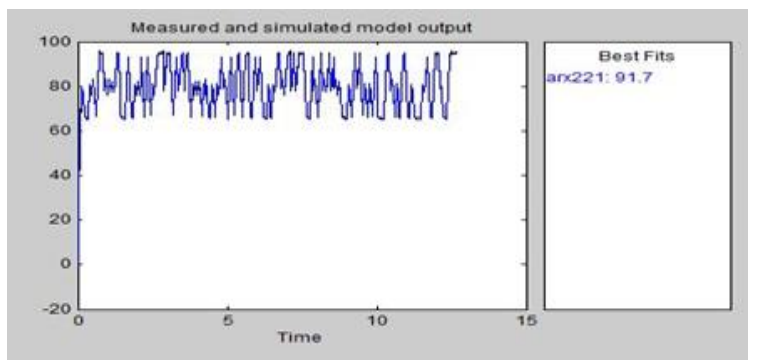

Figure 5. Estimation results for motor 1

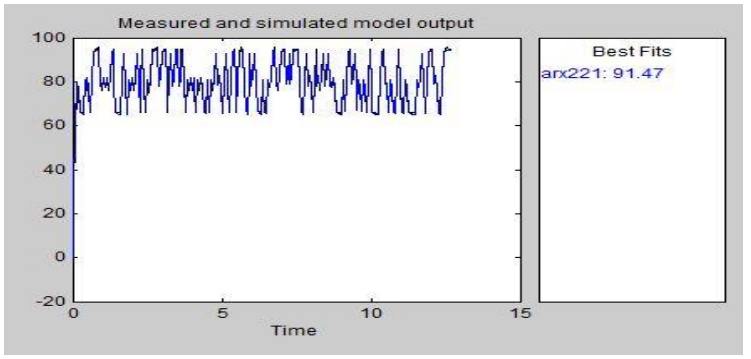

Figure 6. Estimation results for motor 2

The output characteristics of both motors being obtained by implementing a unit step function input, and comparing the rise time and the settling time on both motors, are shown in Figure 7 and Figure 8.

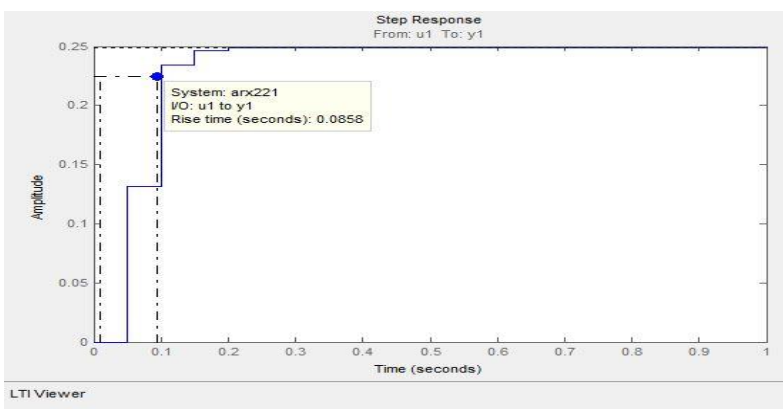

Figure 7. The rise-time output value of the planetary PG36 motor

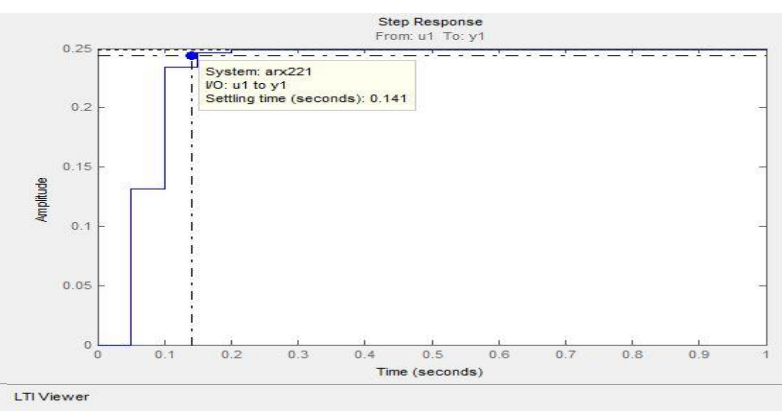

Figure 8. The settling-time output value of the planetary PG36 motor 
As seen in Figure 7 and Figure 8, the difference in the rise-time value of both motors is 0.0004 second, whereas the difference in the settling-time value is 0.003 second. It confirms that the output characteristics of both motors are relatively similar.

In order to obtain the transfer function of the motors, the parameters $a_{1}, a_{2}, b_{1}$, and $b_{2}$ of the ARX model for each motor have been found out. The values for Motor 1 were $\mathrm{a} 1=-0.105$, a2 $=0.161, \mathrm{~b} 1=-0.0312$, and $\mathrm{b}_{2}=0.0888$, whereas for Motor 2 were $\mathrm{a}_{1}=-0.108, \mathrm{a}_{2}=0.1588, \mathrm{~b}_{1}=-0.038861$, and $\mathrm{b}_{2}=0.0888$.

The ARX model parameters were then used in the identification process of both the PG36 DC motor actuator systems, to result in the transfer function as given in Equation 11 for Motor 1 with best-fit value of 91.7 and Equation 12 for Motor 2 with best-fit value of 91.47, respectively.

$\mathrm{Gp}(\mathrm{z})=\frac{\mathrm{B}\left(\mathrm{Z}^{-1}\right)}{\mathrm{A}\left(\mathrm{Z}^{-1}\right)}=\frac{0,161 \mathrm{Z}^{-1}+0.0888 \mathrm{Z}^{-2}}{1-0,105 \mathrm{Z}^{-1}-0,03120 \mathrm{Z}^{-2}}$

$\mathrm{Gp}(\mathrm{z})=\frac{\mathrm{B}\left(\mathrm{Z}^{-1}\right)}{\mathrm{A}\left(\mathrm{Z}^{-1}\right)}=\frac{0,1588 \mathrm{Z}^{-1}+0.0888 \mathrm{Z}^{-2}}{1-0,108 \mathrm{Z}^{-1}-0,038861 \mathrm{Z}^{-2}}$

\subsection{Calculation results of control parameters}

The calculation results of control parameters are given in Table 1, whereas the graphical responses of the Planetary PG36 DC motors, Motor 1 and Motor 2, are given in Figure 9.

Table 1. The control parameters of the Planetary PG36 DC motors

\begin{tabular}{ccccc}
\hline Motor & $q_{0}$ & $q_{1}$ & $q_{2}$ & $p_{1}$ \\
\hline Motor 1 & 2.672993 & -0.0341019 & -0.029879 & -0.756215 \\
Motor 2 & 2.651523 & -0.335160 & -0.018549 & -0.751193 \\
\hline
\end{tabular}

As seen, it gives the parameter values of $\mathrm{q}_{0}=2.672993, \mathrm{q}_{1}=-0.0341019, \mathrm{q}_{2}=-0.029879$, and $\mathrm{p}_{1}=-$ 0.756215 for the first DC motor, and $\mathrm{q}_{0}=2.651523, \mathrm{q}_{1}=-0.335160, \mathrm{q}_{2}=-0.018549$, and $\mathrm{p}_{1}=-0.751193$ for the second DC motor.

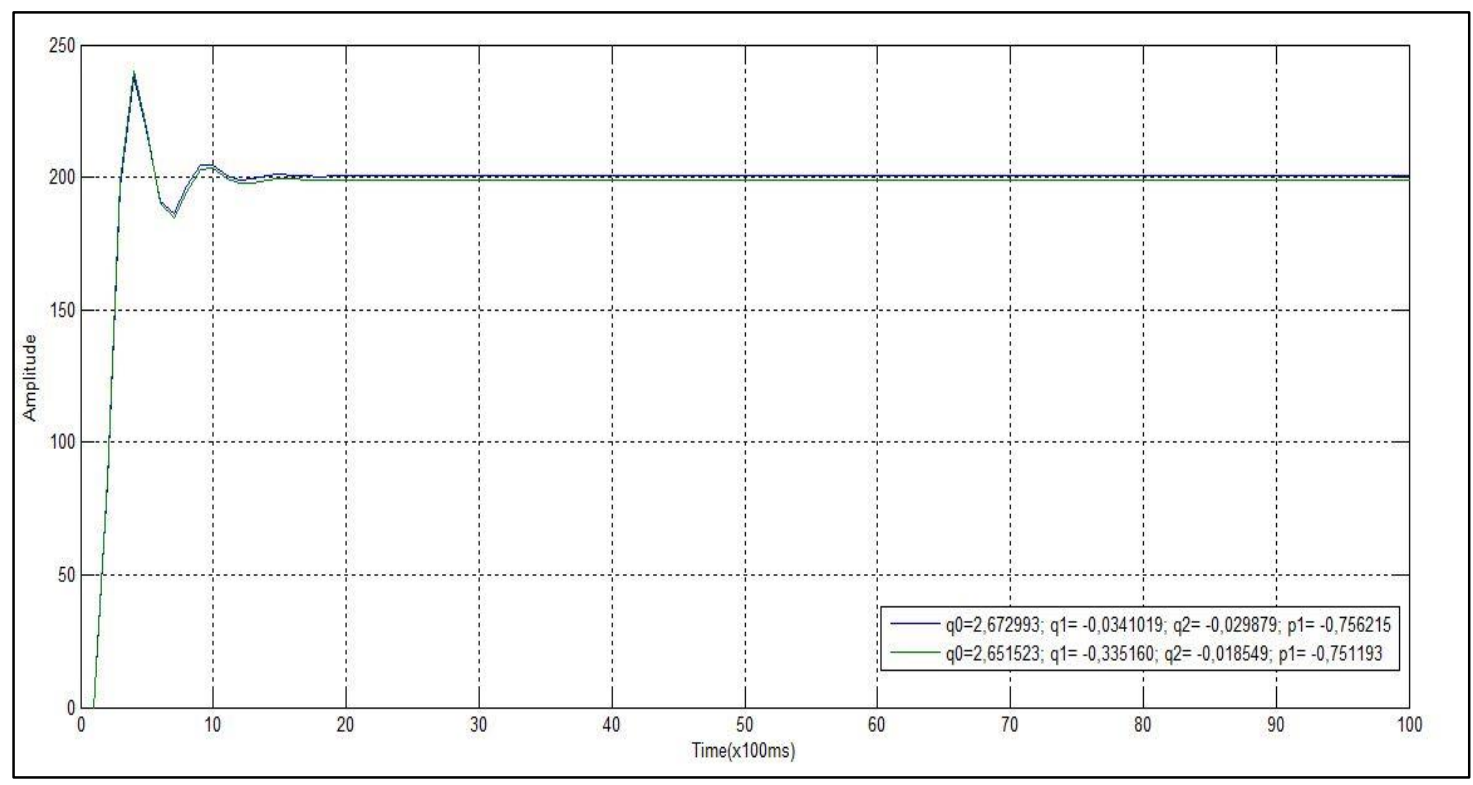

Figure 9. The graphical responses of Planetary PG36 DC motors

As shown in Figure 9, the response of the transfer function being obtained from the identification process of both motors indicates almost similar characteristics. An offset condition is still existing using the setpoint of $200 \mathrm{rpm}$. The best control parameter values obtained is $\mathrm{q}_{0}=2.72993, \mathrm{q}_{1}=-0.0341019$, $\mathrm{q}_{2}=-$ 0.029879 , and $\mathrm{p}_{1}=-0.756215$. 


\subsection{The whole system testing results}

The whole system testing has been done by observing the motor response when being exposed to setpoint changing from 100, 225, and 325 continuously.

The testing has also been done by changing the rotation angle of the rotary sensor using the angle greater than $>35^{\circ}$ in the positive direction, and using the angle greater than $>-35^{\circ}$ in the negative direction alternately. The motor response with respect to the setpoint changing is given in Figure 10.

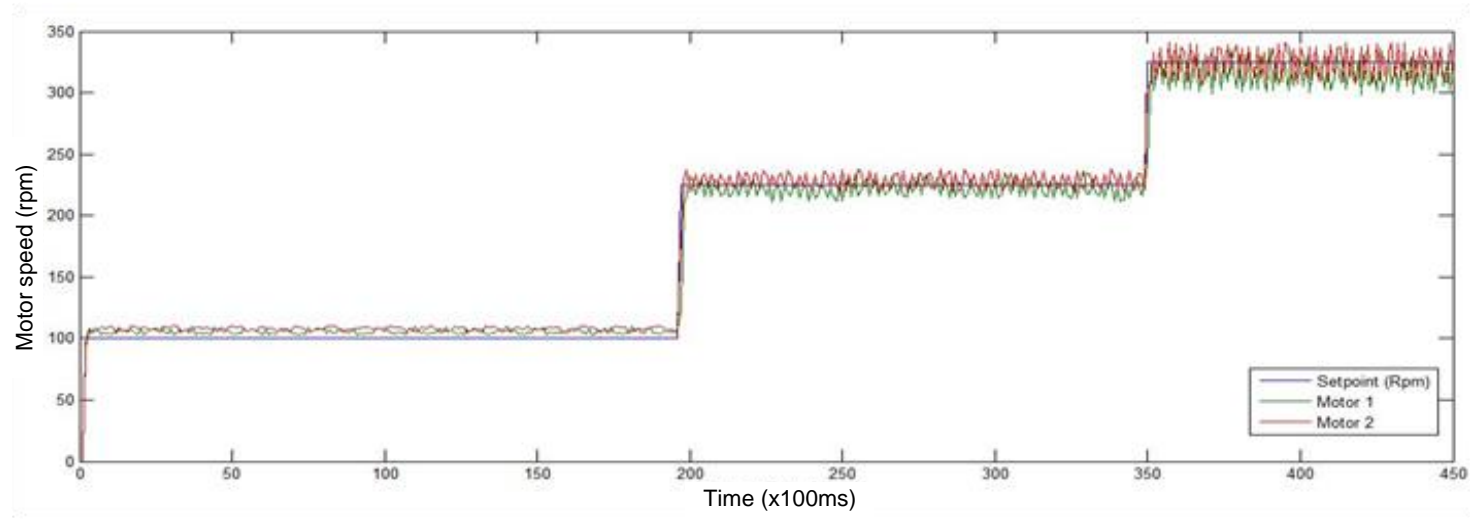

Figure 10. The motor response to the change in the setpoint value

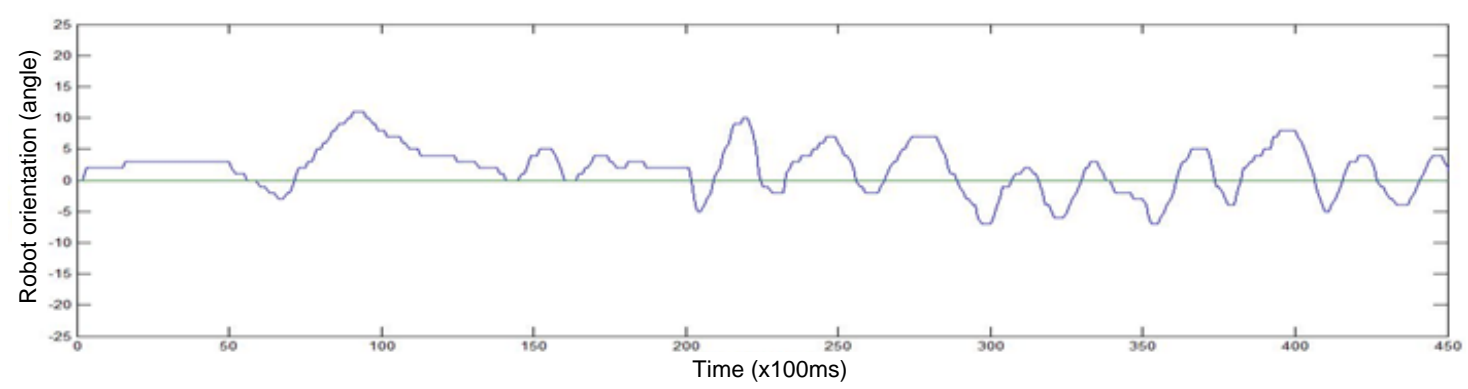

Figure 11 displays the response of both motors at the setpoint of $225 \mathrm{rpm}$

Figure 10 indicates the response of both motors to the speed changing using the setpoint values of 100,225 , and $325 \mathrm{rpm}$. At the setpoint of $100 \mathrm{rpm}$, the settling time is 0.2 second with the steady-state error of $2.2 \%$. At the setpoint of $225 \mathrm{rpm}$, the settling time is 0.25 second with the steady-state error of $2.8 \%$, whereas at the setpoint of $325 \mathrm{rpm}$, the settling time is 0.35 second with the steady-state error of $4.1 \%$.

Figure 11 indicates the condition when the hybrid climbing robot has been exposed to the change in orientation angle of greater than $>35^{\circ}$ in the positive direction and greater than $>-35^{\circ}$ in the negative direction during the climbing process.

Figure 11 displays the response of both motors at the setpoint of $225 \mathrm{rpm}$. It can be seen that the speed responses of both motors are different. At the setpoint of $225 \mathrm{rpm}$, the settling time is 0.15 second with the steady-state error of $2.8 \%$ for Motor 1, whereas for Motor 2 the settling time is 0.2 second with the steady-state error of $2.9 \%$.

By comparing Figure 10 and Figure 11 it can be concluded that during the climbing process at the setpoint of $225 \mathrm{rpm}$ the robot experiences the change in the orientation angle, although it is not too large and still within the angle tolerance of $-10^{\circ}$ to $10^{\circ}$. With the average speed of both motors of $218 \mathrm{rpm}$, the motor responses were different from the setpoint condition when a shifting of robot orientation angle has been done with an angle greater than $35^{\circ}$. The difference in Motor 1 was due to the change in the direction angle greater than $-35^{\circ}$ in the negative direction. Motor 1 tends to maintain its speed at the setpoint value, whereas Motor 2 tends to increase its speed up to $304 \mathrm{rpm}$ until the robot orientation angle goes back to its initial position with orientation angle tolerance of $-10^{\circ}$ to $10^{\circ}$. This condition confirms the results that the robot was capable of 
maintaining its initial position during the occurrence of disturbance in a form of the change in rotation angle, and that the robot was capable of climbing straightly.

\section{CONCLUSION}

The orientation control of pole-climbing robot using self-tuning method has been realized by identifying the transfer function of the actuator system under consideration, being followed with the calculation of the control parameters using the self-tuning pole-placement method, and furthermore being implemented on microcontroller Arduino Mega 2560.

Based on the implementation results, it can be concluded that the control of the robot under consideration could maintain its original position at the time of angle change disturbance and that the robot could climb in straight direction within the specified tolerance of orientation angle change.

The use of more position orientation sensors may result in higher precision and smoothness of robot movement change. The use of DC motor with more variations of speed may produce higher speed response. The use of other types of controllers may increase the robot performance.

\section{REFERENCES}

[1] Das M, Agrawal A, Sonone A, Gupta R, Upadhyay D, Rao YVD, Javed A., "Developing a bioinspired pole climbing robot," IEEE 2016 International Conference on Robotics: Current Trends and Future Challenges (RCTFC). 2016, pp.1-6.

[2] Khalid ZB, Hasib Ullah Md., Ahmed R, Choudhury ZH, Kaish I, Rhaman K., "Electrical pole climbing robot: For wiring and repairing distribution lines," IEEE 2015 18th International Conference on Computer and Information Technology (ICCIT). 2015, pp. 368-372.

[3] Megalingam RK, Reddy SV, Sriharsha G, Surya Teja P, Sai Kumar K, Gopal P., "Study and development of Android controlled wireless pole climbing robot," IEEE 2015 International WIE Conference on Electrical and Computer Engineering (WIECON-ECE). 2015, pp. 439-442.

[4] Li Y, Chen MZQ, Chen YH, Lam J., "Design of a one-motor tree-climbing robot," 2015 IEEE International Conference on Information and Automation. 2015, pp. 26-31.

[5] Nor Faizal MI, Othman WAFW, Syed Hasan SSNA., "Development of pole-like tree climbing robot," 2015 IEEE International Conference on Control System, Computing and Engineering (ICCSCE). 2015, pp. 224-229.

[6] Suparat N, Maneewarn T., "Spraying analysis for a coconut climbing robot." IEEE 2015 7th International Conference on Information Technology and Electrical Engineering (ICITEE). 2015, pp. 388-393.

[7] Wu X, Liu J, Zhou Y, Lv Q, Hu C., "Movement Control and Attitude Adjustment of Climbing Robot on Flexible Surfaces." IEEE Transactions on Industrial Electronics. 2018; 65(3), pp. 2618-2628.

[8] Sun G, Li P, Meng Y, Xu E, Zhou Y, Liu Y., "A climbing robot for inspection of lamppost in the airport: Design and preliminary experiments." 2017 IEEE International Conference on Robotics and Biomimetics (ROBIO). 2017, pp. 436-441.

[9] Boomeri V, Pourebrahim S, Tourajizadeh H., "Kinematic and dynamic modeling of an infrastructure hybrid climbing robot." 2017 IEEE 4th International Conference on Knowledge-Based Engineering and Innovation (KBEI). 2017, pp. 0834-0842.

[10] Ahn KK, Anh HPH., "System Identification and Self-Tuning Pole Placement Control of the Two-Axes Pneumatic Artificial Muscle Manipulator Optimized by Genetic Algorithm." IEEE 2007 International Conference on Mechatronics and Automation. 2007, pp. 2604-2609.

[11] Santro I, Peric N, Petrovic I., "Comparison of the self-tuning generalized predictive controller and pole placement controller." 9th Mediterranean Electrotechnical Conference, 1998. MELECON 98. 1998; 1, pp. 539-543.

[12] Hang CC, Cai YS, Lim KW., "A dual-rate self-tuning pole-placement controller." IEEE Transactions on Industrial Electronics. 1993; 40(1), pp. 116-129.

[13] McAskill B, Dunford WG., "Self-tuning pole placement control of a manipulator with flexible joints." 19th Annual IEEE Power Electronics Specialists Conference, 1988. PESC '88 Record. 1988; 1, pp.445-451.

[14] Puthenpura SC, MacGregor JF., "Pole-zero placement controllers and self-tuning regulators with better set-point tracking." IEE Proceedings D - Control Theory and Applications. 1987; 134(1), pp. 26-30.

[15] Walters RG, Bayoumi MM., "Application of a self-tuning pole-placement regulator to an industrial manipulator." 198221 st IEEE Conference on Decision and Control. 1982, pp. 323-329.

[16] Shimada A, Sonoda K, Satoh Y., "Sensor-less grasping control on two-fingered robot hands." IEEE 2009 ICCASSICE. 2009, pp. 40-45.

[17] Kumar VN, Syed A, Kuruganti D, Egoor A, Vemuri S., "Measurement of position (angle) information of BLDC motor for commutation used for e-bike." 2013 International Conference on Advanced Electronic Systems (ICAES). 2013, pp. 316-318.

[18] San-Millan A, Feliu V, Garcia A., "A two-stage control scheme of single-link flexible manipulators." $201523 \mathrm{rd}$ Mediterranean Conference on Control and Automation (MED). 2015, pp. 1098-1105. 
[19] Grigorov IV, Atanasov NR., "Application of recursive methods for parameter estimation in adaptive pole placement control of DC motor." 2017 15th International Conference on Electrical Machines, Drives and Power Systems (ELMA). 2017, pp. 215-218.

[20] Xu Y, Miao YZ, Fan L., "Deriving ARX models for synchronous generators." 2016 North American Power Symposium (NAPS). 2016, pp. 1-6.

[21] Wu A-G, Wang Z-G., "Modified recursive extended least squares identification algorithms." IEEE 2013 25th Chinese Control and Decision Conference (CCDC). 2013, pp. 1562-1567.

[22] Yeredor A., "The extended least squares criterion: minimization algorithms and applications." IEEE Transactions on Signal Processing. 2001; 49(1), pp. 74-86.

[23] Radenkovic MS, Michel AN., "Bursting Phenomena in Extended-Least Squares Based Self-Tuning Control." IEEE 1993 American Control Conference. 1993, pp. 296-300.

[24] Astrom KJ, Hagglund T., "PID Controllers: Theory, Design and Tuning." Instrument Society of America: Research Triangle Park. 1995.

[25] Landau ID, Zito G., "Digital Control Systems: Design, Identification and Implementation." Germany: Springer. 2006.

[26] Sarığlu A, Kural A., "Modeling and ARX identification of a quadrotor MiniUAV." 2015 9th International Conference on Electrical and Electronics Engineering (ELECO). 2015, pp. 1196-1200.

[27] Soderstrom T, Fan H, Carlsson B, Bigi S., "Least squares parameter estimation of continuous-time ARX models from discrete-time data." IEEE Transactions on Automatic Control. 1997; 42(5), pp. 659-673.

[28] Bobál V, Böhm J, Fessl J, Machácek J., "Digital Self-tuning Controllers: Algorithms, Implementation and Applications." London, UK: Springer. 2005. 